\title{
Uptake and metabolism of propionate in the liver isolated from sheep treated with glucagon
}

\author{
BY ABDULHAMID MOHAMED ALI AND MARKANDEYA JOIS \\ School of Agriculture, Faculty of Science and Technology, La Trobe University, Bundoora, Victoria, \\ Australia 3083
}

(Received 2 January 1996 - Revised 4 June 1996 - Accepted 8 October 1996)

\begin{abstract}
The uptake and metabolism of propionate in the isolated perfused caudal lobe of the liver and in isolated hepatocytes were examined following treatment of sheep with glucagon or saline. Glucagon or sterile saline was infused at $9.8 \mu \mathrm{g} / \mathrm{min}$ for $3 \mathrm{~h}$ into the jugular vein and then the caudal lobe of the liver was removed surgically under anaesthesia. The caudal lobe was used either to prepare hepatocytes or in a non-recirculating perfusion experiment. Uptake and metabolism of propionate were studied using $\left[2-{ }^{14} \mathrm{C}\right.$ ]propionate. In studies using the non-recirculation perfusion of the caudal lobe of the sheep liver it was shown that the treatment of sheep with glucagon resulted in an increased rate of gluconeogenesis from propionate and in an increased net uptake of propionate by the caudal lobe. The uptake of propionate into the hepatocytes was saturable, concentrative and exhibited a $K_{\mathrm{m}}$ for propionate of 0.24 (SE 0.07 ) $\mathrm{mM}$ and a maximal rate of uptake $\left(\mathrm{V}_{\max }\right.$ ) of 6.7 (SE 0.6) $\mathrm{nmol} / \mathrm{mg}$ dry cells per min and was unaffected by glucagon treatment of sheep. After incubation of cells in medium containing $0.5 \mathrm{~mm}-\left[2-{ }^{14} \mathrm{C}\right]$ propionate for $10 \mathrm{~min}$, the rate of gluconeogenesis from propionate was $22 \%$ higher in the hepatocytes isolated from glucagon-treated sheep. Concentrations in the medium of $1.35 \mathrm{~mm}$ butyrate and $1 \mathrm{mM}$-caproate inhibited propionate uptake by about $50 \%$ and abolished the glucagon-induced stimulation of gluconeogenesis from propionate. The results are consistent with a regulatory role for glucagon in the gluconeogenesis from propionate in the sheep liver.
\end{abstract}

Propionate: Glucagon: Non-recirculating perfusion model

Ruminants rely on hepatic gluconeogenesis from propionate to meet their requirements for glucose (Bergman et al. 1966; Bergman \& Wolff, 1971; Bergman, 1990). Propionate which is produced during bacterial fermentation of carbohydrates in the rumen and absorbed into the portal vein is rapidly removed from blood by the liver (Bergman \& Wolff, 1971). Despite the fact that the pathway for glucose synthesis from propionate is well established, the control mechanisms of this pathway in the ruminant liver are poorly understood (Gill et al. 1985; Faulkner \& Pollock, 1986; Demigné et al. 1991). While the amount of propionate absorbed from the rumen and supplied to the liver is undoubtedly a major factor in the regulation of hepatic gluconeogenesis from propionate (Bergman et al. 1966; Judson et al. 1968), there is considerable controversy regarding the role of hormones in the regulation. For example, in vitro studies on the effects of glucagon on gluconeogenesis from propionate using isolated ovine hepatocytes have reported stimulation (Clark et al. 1976; Looney et al. 1987; Faulkner \& Pollock, 1990; Donkin \& Armentano, 1995) as well as no stimulation (Savan et al. 1986). In the in vivo study of Brockman \& Greer (1980) on the effects of glucagon on the utilization of propionate, the glycogenolytic and gluconeogenic effects of glucagon could not be separated and the authors could only conclude that the stimulation of gluconeogenesis by glucagon was not selective to gluconeogenesis from 
propionate as compared with other gluconeogenic precursors. Therefore, a regulatory role for glucagon in gluconeogenesis from propionate cannot be ruled out.

A major drawback of previous in vitro studies on the regulation of propionate metabolism using isolated cells and isolated perfused liver is the excessive concentration of propionate in the medium used. Due to the rapid uptake and utilization of propionate by the liver, these studies have used a concentration of propionate in the incubation and perfusion media $(2.5 \mathrm{mM}$ and above) which is many times higher than the physiological concentration of propionate in the portal blood $(0.1$ to $0.5 \mathrm{mM})$ (Bergman \& Wolff, 1971) to avoid rapid changes in propionate levels in the medium and to prevent substrate depletion within the duration of incubation and/or perfusion. These high concentrations of propionate in the medium, however, result in rapid depletion of mitochondrial ATP pools (Hampson et al. 1984) and in the accumulation of propionyl CoA in the mitochondria (Brass et al. 1986). Information on the regulation of propionate metabolism obtained in these in vitro systems may not be relevant under physiological conditions. It is therefore of interest to develop in vitro systems for studies on propionate metabolism which allow use of a constant and physiological concentration of propionate in the medium. In the present study we used a non-recirculating perfusion system of caudal lobe of sheep liver, which allowed maintenance of a constant and physiological concentration of propionate in the medium, to study the effects of glucagon on propionate metabolism. Glucagon was administered in vivo before the animals were-killed to isolate the caudal lobe of the liver. In separate studies, uptake and metabolism of propionate by hepatocytes isolated from control and glucagon-treated sheep were also examined. In studies using rats it has been shown that the effects of administration of glucagon in vivo can be demonstrated in vitro in isolated hepatocytes and hepatic mitochondria isolated from these animals (Adams \& Haynes, 1969; Jensen et al. 1983; Jois et al. 1989). The results from the present study demonstrate that the isolated caudal lobe and the hepatocytes isolated from glucagon-treated sheep show increased rates of gluconeogenesis from propionate.

\section{MATERIALS AND METHODS}

The experimental protocol and procedures were in accordance with the Australian code of practice for the care and use of animals for scientific purposes and were approved by the Animal Experimentation Ethics Committee of La Trobe University.

\section{Animals and diet}

Nine cross-bred male lambs (24-35 kg live weight) were used in experiments using isolated hepatocytes and eight merino female lambs $(24-35 \mathrm{~kg}$ live weight) were used in the experiments using the isolated perfused caudal lobe of the liver. The animals were maintained on a good quality pasture for at least 2 months before the studies. At least 1 week before the start of the experiment, the animals were penned individually indoors and offered a maintenance diet of $800 \mathrm{~g}$ lucerne (Medicago sativa) chaff and $200 \mathrm{~g}$ grain-based pellets daily at 10.00 hours. Water was provided ad libitum.

\section{Experimental procedures}

Hormone infusions. At least $1 \mathrm{~d}$ before experimentation a polyvinyl catheter $(1.0 \mathrm{~mm}$ i.d., $1.5 \mathrm{~mm}$ o.d., Dural Plastics, Sydney, Australia) was placed in each external jugular vein of each sheep (one catheter for infusion and the other for taking blood samples). The catheters were kept patent between sampling times by filling the catheter tubings with sterile saline containing $100 \mathrm{U}$ heparin $/ \mathrm{ml}$. The animals were not offered feed on the day of the 
experiment and any feed residues from the previous day were removed $1 \mathrm{~h}$ before giving the infusions. Glucagon or sterile saline (control group) was infused over $3 \mathrm{~h}$ into the jugular vein. A mixture of bovine-porcine glucagon (Sigma Chemical Co., St Louis, MO, USA) made up in sterile saline containing bovine albumin $(2 \mathrm{~g} / \mathrm{l})$ was infused at $9.8 \mu \mathrm{g} / \mathrm{min}$. All the solutions were delivered at $0.37 \mathrm{ml} / \mathrm{min}$. The rate of glucagon infusion was calculated to be about five times the rate used by Brockman \& Bergman (1975) who infused glucagon into the mesenteric vein. The rate of infusion into the jugular catheter was increased because the concentration of glucagon in the portal vein is about five times the concentration in the general circulation. Blood samples $(10 \mathrm{ml})$ were taken into heparinized syringes $(50 \mathrm{IU} / \mathrm{ml}$ blood) before the start of the infusion $(0 \mathrm{~min})$ and after $30,60,90,120,150$ and $180 \mathrm{~min}$ of infusion. The plasma was harvested and stored at $-20^{\circ}$ until analysed for glucose by the glucose oxidase (EC 1.1.3.4) method (Bergmeyer \& Bernt, 1974) and for glucagon by radioimmunoassay using a commercial kit (ICN Pharmaceuticals, Inc., CA, USA).

Perfusion of caudal lobe. At the end of the $3 \mathrm{~h}$ of infusion, sheep were anaesthetized with pentobarbitone sodium $(15 \mathrm{mg} / \mathrm{kg}$ live weight) and $1 \mathrm{ml}$ of a solution of heparin containing $25000 \mathrm{U}$ heparin was infused into the jugular vein. The animal was placed in lateral recumbency, the abdominal cavity was opened and the liver and hepatic portal vein were exposed. The caudal lobe was excised with about $30 \mathrm{~mm}$ of portal vein intact. The portal vein was cut open and the exit point of the branch supplying the caudal lobe was located. A catheter was fitted snugly into the portal branch supplying the caudal lobe. The branch of the hepatic vein exiting the caudal lobe was located and another catheter was introduced. The caudal lobe was perfused via the portal branch and the perfusate was collected via the hepatic venous catheter. The perfusion system was essentially the same as the non-recirculating perfusion system described previously for rat liver (Siess, 1978). The perfusion medium consisted of Krebs-Henseleit medium, $2.1 \mathrm{~mm}$-lactate, $0.3 \mathrm{mM}-$ pyruvate, $0.5 \mathrm{mM}-\left[2-{ }^{14} \mathrm{C}\right]$ propionate, $0.1 \mathrm{mM}$-butyrate, $1.5 \mathrm{mM}$-acetate, $0.15 \mathrm{~mm}$-alanine, $0.2 \mathrm{mM}$-glutamine, and $4.0 \mathrm{mM}$-glucose. The volatile fatty acids, alanine, glutamine and glucose were added to simulate concentrations of these substrates in sheep (Bergman \& Wolff, 1971; Brockman \& Bergman, 1975). The reservoir containing the perfusion medium was kept in a water bath maintained at $37^{\circ}$ while gassing it with $\mathrm{O}_{2}-\mathrm{CO}_{2}$ $(95: 5, \mathrm{v} / \mathrm{v})$, to bring the $\mathrm{pH}$ to 7.4 . The entire procedure from anaesthesia to the start of perfusion took less than $2 \mathrm{~min}$. The perfusion medium was pumped from the reservoir to the multibulb oxygenator (Krebs et al. 1974) of the perfusion system at a rate of $120 \mathrm{ml} / \mathrm{min}$. The perfusion medium overflow from the multibulb oxygenator back to the reservoir varied from 20 to $40 \mathrm{ml}$ giving a flow rate through the liver of between 80 and $100 \mathrm{ml} / \mathrm{min}$. Flow rate $(\mathrm{ml} / \mathrm{min})$ was measured every $4 \mathrm{~min}$ by collection of the effluent from the hepatic venous catheter. Any perfusate leaked through was measured by collection of the leaked perfusate through a hole made at the bottom of the organ chamber into a beaker. The proportion of the perfusion medium leaked around the entry of the portal cannula was estimated by comparing the amounts of $\left[{ }^{14} \mathrm{C}\right]$ glucose in the leaked perfusate and in the effluent collected via the hepatic catheter. The total leakage was generally about $10 \%$ of the total flow rate and less than $5 \%$ of the total leakage was around the portal cannula. Preliminary work showed that the rate of gluconeogenesis from propionate reached a plateau within the first $5 \mathrm{~min}$ and was maintained at this rate for up to $50 \mathrm{~min}$. However, the period of perfusion was limited to $25 \mathrm{~min}$ to minimize costs. Samples of effluent $(20 \mathrm{ml})$ from the hepatic venous catheter were taken at intervals of $5 \mathrm{~min}$. A portion of $10 \mathrm{ml}$ was transferred quickly into an Erlenmeyer flask (25 ml capacity) for measurement of ${ }^{14} \mathrm{CO}_{2}$ to estimate oxidation of propionate. The ${ }^{14} \mathrm{CO}_{2}$ in the perfusion medium was collected and counted as described previously (Jois et al. 1989). Another 
portion of $10 \mathrm{ml}$ was stored at $-20^{\circ}$ until analyses for separation of $\left[{ }^{14} \mathrm{C}\right]$ glucose from $\left[{ }^{14} \mathrm{C}\right]$ propionate by anion exchange chromatography and for determination of propionate by GLC after freeze-transfer extraction (Pethick et al. 1981). Extraction (\%) of propionate was calculated as $((I-E) / I) \times 100$ where $I$ is the concentration of propionate $(\mathrm{mM})$ in the perfusion medium and $E$ is the concentration of propionate ( $\mathrm{mM}$ ) in effluent. Net uptake was calculated as $(I-E) \times$ flow rate (litres $/ g$ liver per min).

Preparation of hepatocytes. Hepatocytes were isolated from the caudal lobe by a twostep collagenase digestion method. The caudal lobe was perfused via the portal catheter with about $500 \mathrm{ml} \mathrm{Ca}{ }^{2+}$-free Krebs-Henseleit medium containing $1 \mathrm{mM}$-(ethylenebis(oxyethylene-nitrilo))tetraacetic acid (EGTA) followed by $200 \mathrm{ml} \mathrm{Krebs-Henseleit}$ medium containing $1.25 \mathrm{mM} \mathrm{CaCl}_{2}$ and the perfusates were discarded. The caudal lobe was then perfused with $200 \mathrm{ml}$ Krebs-Henseleit medium containing $72 \mathrm{mg}$ collagenase ( $E C$ 3.4.24.3; Boehringer-Mannheim, NSW, Australia) with recirculation of the perfusate. The remaining steps of digestion, and isolation of hepatocytes were as described by Krebs $e t$ al. (1974). Over $95 \%$ of cells excluded trypan blue when included in the incubation medium $(2 \mathrm{~g} / 1)$.

Gluconeogenesis from propionate in isolated hepatocytes. Gluconeogenesis from propionate was determined by measuring production of ${ }^{14} \mathrm{C}$-labelled glucose from $0.5 \mathrm{mM}$ $\left[2-{ }^{14} \mathrm{C}\right]$-labelled propionate. Hepatocytes $(3-5 \mathrm{mg}$ dry cells $/ \mathrm{ml})$ were preincubated, in triplicate, for $10 \mathrm{~min}$ in $2 \mathrm{ml} \mathrm{Krebs-Henseleit} \mathrm{medium} \mathrm{containing} 2.1 \mathrm{mM}$-lactate, $0.3 \mathrm{mM}$ pyruvate, $0.1 \mathrm{mM}$-butyrate, $1.5 \mathrm{mM}$-acetate, $0.15 \mathrm{mM}$-alanine, $0.2 \mathrm{mM}$-glutamine, and 4.0 mM-glucose and gassed with $\mathrm{O}_{2}-\mathrm{CO}_{2}(95: 5, \mathrm{v} / \mathrm{v})$. The incubations were carried out in a shaking water bath at $37^{\circ}$ in stoppered $25 \mathrm{ml}$ Erlenmeyer flasks. The reaction was initiated by adding $20 \mu \mathrm{l} 50 \mathrm{mM}-\left[2-{ }^{14} \mathrm{C}\right]$ sodium propionate $(0.33 \mathrm{kBq} / \mu \mathrm{mol})$, incubated for another $10 \mathrm{~min}$ before stopping the reaction by addition of $0.2 \mathrm{ml} 3 \mathrm{M}-\mathrm{HClO}_{4}$. The incubation period of $10 \mathrm{~min}$ was chosen after preliminary experiments showed that under these conditions of cell density and propionate concentration, gluconeogenesis from propionate was linear up to $15 \mathrm{~min}$. The samples were then centrifuged and the supernatant fractions were neutralized with $5 \mathrm{M}-\mathrm{K}_{2} \mathrm{CO}_{3}$. The conversion of ${ }^{14} \mathrm{C}$-labelled propionate into glucose was determined by separating glucose from propionate using anion exchange columns. A $1 \mathrm{ml}$ sample of the neutralized supernatant fraction was applied to minicolumns of Dowex AG1-X8 (100-200 mesh, acetate form). The columns were eluted five times each with $1 \mathrm{ml}$ deionized water, and another five times each with $3 \mathrm{M}-\mathrm{NaCl}$. The fractions were collected separately in scintillation vials, each containing $10 \mathrm{ml}$ scintillation fluid (Ultima Gold, Packard Instruments, USA) and counted in a liquid scintillation counter (RackBeta, Wallac OY, Turku, Finland).

Uptake experiments. Propionate transport was initiated by adding appropriate amounts of $\left[2-{ }^{4} \mathrm{C}\right]$ propionate $(1.68 \mathrm{kBq} / \mu \mathrm{mol})$ to the flasks containing hepatocytes to achieve the desired initial concentration of propionate in the incubation medium. Incubations were carried out for 10-30 s to determine the rate of transport of propionate. Transport rates of propionate were measured after preincubation of cells for $10 \mathrm{~min}$. When indicated, $1.35 \mathrm{mM}$-butyrate or $1 \mathrm{mM}$-caproate were included in the medium to inhibit gluconeogenesis from propionate (Demigné et al. 1986; Aiello et al. 1989; Chow \& Jesse, 1992). At the end of the incubations, portions $(0.5 \mathrm{ml})$ from each flask were placed carefully on top of 1bromododecane $(0.5 \mathrm{ml})$ layered on the top of $50 \mu \mathrm{l} 3 \mathrm{M}-\mathrm{HClO}_{4}$ in an Eppendorf tube $(1.5 \mathrm{ml}$ capacity). Cells were separated from the medium by rapid centrifugation $(16000 \mathrm{~g}$, $15 \mathrm{~s}$ ) in an Eppendorf centrifuge 5415C (Hamburg, Germany) and the Eppendorf tube was then quickly plunged into liquid $\mathrm{N}_{2}$. The bottom of the microtube (containing the cell pellets in $\mathrm{HClO}_{4}$ ) was cut about $4 \mathrm{~mm}$ above the lower meniscus of the oil layer and 
transferred into a counting vial. About $8 \mathrm{ml}$ scintillation liquid was added to each counting vial which was then counted for radioactivity as described earlier.

Intracellular concentration of propionate. Intracellular concentration of propionate was measured in hepatocytes incubated in media containing various concentrations of propionate and, when indicated, in the presence of $1.35 \mathrm{mM}$-butyrate or $10 \mu \mathrm{M}$-rotenone. For the determination of intracellular concentrations of propionate, the incubations were carried out for $10 \mathrm{~min}$ in a total volume of $6 \mathrm{ml}$. At the end of the incubations, a portion of $5 \mathrm{ml}$ of each incubation mixture containing hepatocytes was placed on top of $4.5 \mathrm{ml} 1$ bromododecane layered on top of $0.5 \mathrm{ml} 3 \mathrm{M}-\mathrm{HClO}_{4}$ and immediately centrifuged for $2 \mathrm{~min}$ at $2000 \mathrm{~g}$. The layer above the bromododecane consisted of the medium without the cells and the layer below the bromododecane consisted of $\mathrm{HClO}_{4}$ plus the deproteinized cell pellet. A portion $(100 \mu \mathrm{l})$ of the incubation mixture devoid of cells and the $\mathrm{HClO}_{4}$ layer were used to determine the concentration of propionate by GLC after freeze-transfer extraction (Pethick et al. 1981). For determination of intracellular concentration of propionate from these data, it was necessary to measure intracellular volume and to correct for any medium propionate trapped between cells and carried down to the $\mathrm{HClO}_{4}$ layer. This was achieved, in parallel incubations, by determining the total water and extracellular (medium) water carried down to the $\mathrm{HClO}_{4}$ layer using $\left[{ }^{14} \mathrm{C}\right]$ sucrose as described by Jois $e t$ al. (1989). Of the total water carried down to the acid layer, 71 (SE 4)\% was due to intracellular water and the remaining 29 (SE 4) \% was due to extracellular water (incubation medium).

The two-tailed Student's $t$ test was used to compare treatment means.

\section{RESULTS}

\section{Plasma glucose concentrations}

Concentrations of plasma glucose during in vivo infusions of saline and glucagon are presented in Fig. 1. Infusion of glucagon resulted in a prompt increase in the concentration

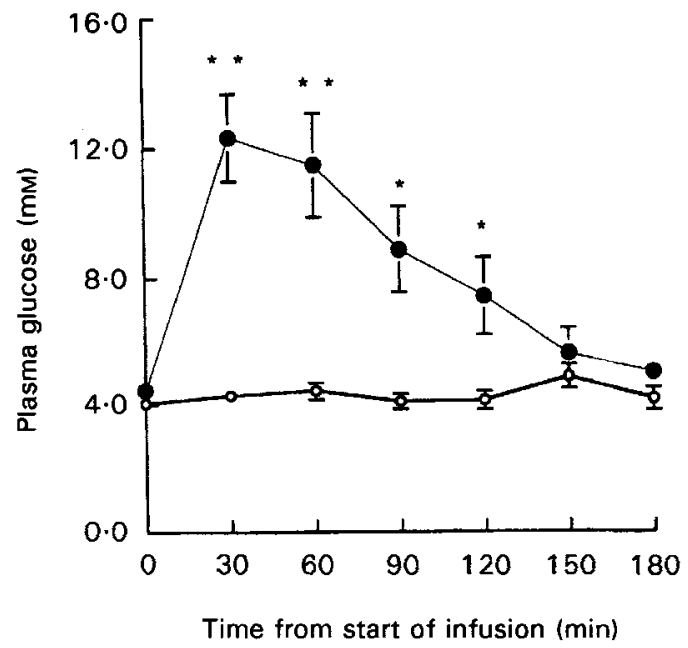

Fig. 1. Plasma glucose before and during infusion of saline $(O)$ or glucagon $(O)$ into the jugular vein of sheep for $3 \mathrm{~h}$. Values are means for four animals with their standard errors indicated by vertical bars. Student's $t$ test revealed a significant increase of plasma glucose in the glucagon group compared with the control group: $* P<0.05, * * P<0.01$. For details of infusions and procedures see pp. 784-785. 
of plasma glucose. During glucagon infusion, the concentration of glucose reached a peak by $30 \mathrm{~min}$ and a rapid decline in the concentration was observed between 60 and $180 \mathrm{~min}$. The circulating concentrations of glucagon, measured in jugular venous blood of one sheep at times $0,30,60,90,120$ and $150 \mathrm{~min}$ were $240,2628,1941,2082,2400$ and $2395 \mathrm{pg} / \mathrm{ml}$ respectively. The peak concentration of glucagon is about five times the concentration of glucagon in jugular venous blood of sheep after feeding (Bassett, 1972).

\section{Metabolism of propionate in the isolated perfused caudal lobe}

The effects of glucagon on the perfusion flow rate, extraction, net uptake and oxidation of propionate and on gluconeogenesis from propionate are presented in Table 1. The perfusion flow rates were similar through the caudal lobes obtained from control and glucagon-treated sheep. The caudal lobes of sheep treated with glucagon showed higher net uptake $(+58 \%)$, higher extraction $(+22 \%)$ and increased rate of gluconeogenesis from propionate $(+35 \%)$ when compared with the caudal lobes of the control group. The rate of oxidation of propionate was similar in both the groups and accounted for only $2-3 \%$ of the net uptake of propionate. Assuming $2 \mathrm{~mol}$ of propionate is used in the synthesis of $1 \mathrm{~mol}$ of glucose it could be calculated that 79 and $63 \%$ of the propionate taken up was released as glucose in the control and glucagon groups respectively.

\section{Uptake and conversion of propionate into glucose in the hepatocytes}

The uptake of propionate into hepatocytes was linear up to $60 \mathrm{~s}$ in lambs infused with either glucagon or saline (Fig. 2). No radioactivity could be detected in the glucose fraction of these samples (up to $60 \mathrm{~s}$ incubation) when separated by anion exchange chromatography (results not shown). The data for transport when hepatocytes were incubated in the presence of $0.05-1 \mathrm{mM}$-propionate for $30 \mathrm{~s}$ are presented in Fig. 3. The transport of propionate into the hepatocytes was saturable and the calculated $K_{\mathrm{m}}$ for propionate and maximal rate of uptake $\left(\mathrm{V}_{\max }\right)$ were 0.24 (SE 0.07) $\mathrm{mM}$ and 6.7 (SE 0.6) nmol $/ \mathrm{mg}$ dry cells per min for the hepatocytes isolated from the control group and 0.20 (SE 0.04) mM and 6.2 (SE 0.41$) \mathrm{nmol} / \mathrm{mg}$ dry cells per min for the hepatocytes isolated from animals treated with glucagon.

Table 1. Extraction, net uptake and oxidation of propionate, and gluconeogenesis from propionate in perfused caudal lobe of the liver from sheep previously infused with glucagon or saline $\dagger$

(Values are means with their standard errors for four animals)

\begin{tabular}{|c|c|c|c|c|}
\hline & \multicolumn{2}{|c|}{ Control } & \multicolumn{2}{|c|}{ Glucagon } \\
\hline & Mean & SE & Mean & SE \\
\hline Flow rate (ml/g wet liver per min) & 5.63 & 0.72 & 6.49 & 0.54 \\
\hline Extraction of propionate (\%) & 44.92 & $4 \cdot 15$ & $55 \cdot 17 *$ & 1.85 \\
\hline Net uptake of propionate ( $\mu \mathrm{mol} / \mathrm{g}$ wet liver per min) & $1 \cdot 12$ & 0.08 & $1.77 * *$ & 0.17 \\
\hline Glucose from $\left[2-{ }^{14} \mathrm{C}\right]$ propionate (nmol/g wet liver per min) & 441.85 & 29.6 & $555.93 *$ & $48 \cdot 45$ \\
\hline Release of ${ }^{14} \mathrm{CO}_{2}(\mathrm{nmol} / \mathrm{g}$ wet liver per min) & 28.65 & 2.43 & 30.93 & 2.76 \\
\hline
\end{tabular}

Mean values were significantly different from those for controls: $* P<0.05, * * P<0.01$ (a two-tail Student's $t$ test). $\uparrow$ The caudal lobe of the liver was perfused in a non-recirculating perfusion system for 25 min with medium containing $0.5 \mathrm{mM}\left[2 .{ }^{14} \mathrm{C}\right]$ propionate. For details of procedures, see pp. $784-786$. 


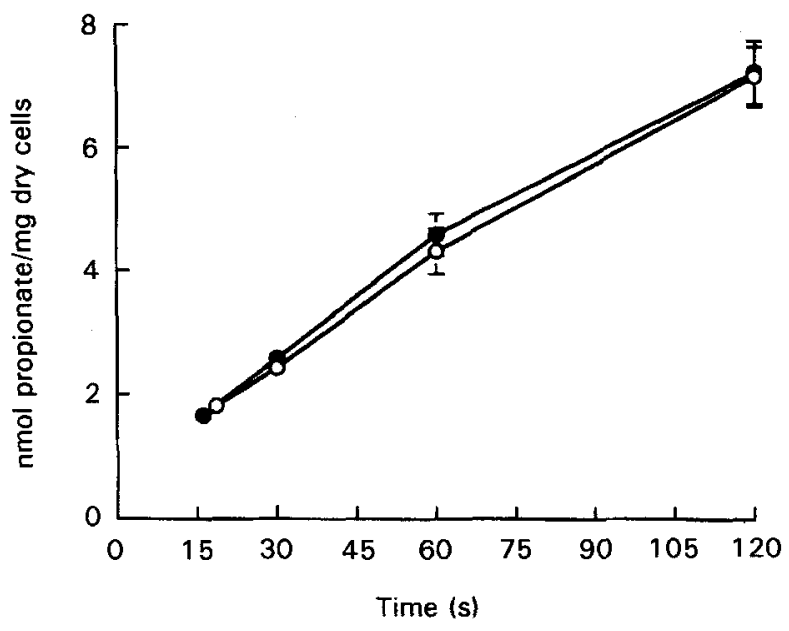

Fig. 2. Time course of the transport of propionate into hepatocytes. Hepatocytes were prepared from sheep treated with either saline $(O)$ or glucagon $(O)$ and incubated in the presence of $0.5 \mathrm{~mm}-\left[2-{ }^{14} \mathrm{Clpropionate}\right.$. For details of procedures see pp. 784-787.

The effects of $1.35 \mathrm{mM}$-butyrate and $1 \mathrm{mM}$-caproate on the transport of propionate into the hepatocytes and on gluconeogenesis from propionate in hepatocytes isolated from control and glucagon-treated sheep are presented in Table 2. Hepatocytes isolated from glucagon-treated sheep showed an increase of $22 \%$ in the rate of gluconeogenesis from propionate. Both butyrate and caproate completely abolished the increase in gluconeogenesis observed in hepatocytes isolated from glucagon-treated sheep. Glucagon treatment of sheep did not affect the transport of propionate. Butyrate and caproate inhibited the transport of propionate by 64 and $50 \%$ respectively.

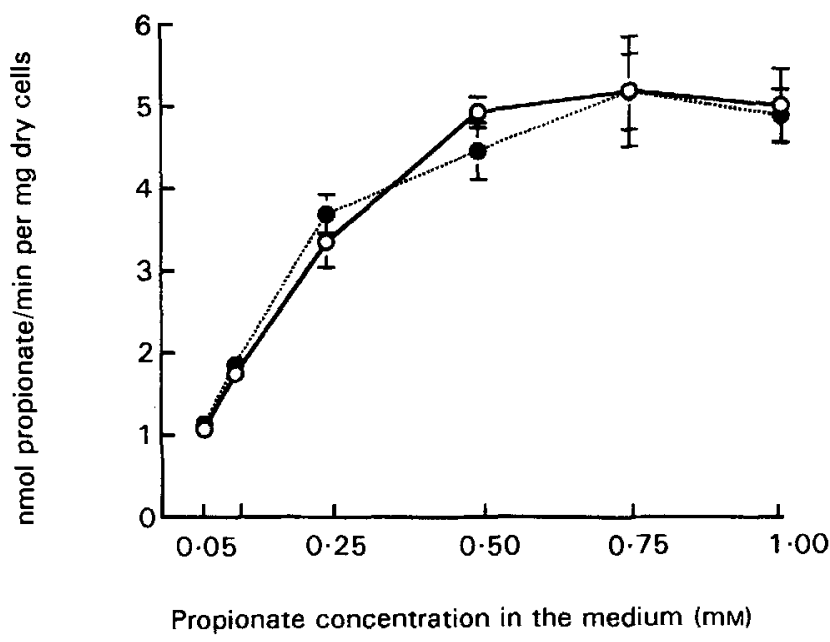

Fig. 3. Transport of propionate into isolated hepatocytes. Hepatocytes were prepared from sheep treated with either saline $(O)$ or glucagon $(O)$ and incubated for $30 \mathrm{~s}$ in the presence of $\left[2-{ }^{14} \mathrm{C}\right]$ propionate at the concentrations shown. For details of procedures see pp. 784-787. 
Table 2. Effects of butyrate $(1.35 \mathrm{mM})$ and caproate $(1 \mathrm{mM})$ on the transport of and on gluconeogenesis from $\left[2-{ }^{14}\right.$ C]propionate in isolated sheep hepatocytes $\dagger$

(Values are means with their standard errors for five animals in the glucagon group and four in the control group)

\begin{tabular}{|c|c|c|c|c|c|c|c|}
\hline \multirow[t]{2}{*}{ Inhibitor added. } & & \multicolumn{2}{|c|}{ None } & \multicolumn{2}{|c|}{ Butyrate } & \multicolumn{2}{|c|}{ Caproate } \\
\hline & & Mean & $\mathrm{SE}$ & Mean & SE & Mean & SE \\
\hline \multicolumn{8}{|c|}{$\begin{array}{l}\text { Transport of propionate (nmol propionate/ } \\
\text { min per mg dry wt cells) }\end{array}$} \\
\hline & Control & $5 \cdot 58^{a}$ & 0.21 & $2 \cdot 0^{\mathrm{b}}$ & 0.17 & $2 \cdot 8^{\mathrm{c}}$ & $0 \cdot 14$ \\
\hline & Glucagon & $5 \cdot 29^{\mathrm{a}}$ & 0.26 & $1.74^{\mathrm{b}}$ & 0.13 & $2 \cdot 44^{c}$ & 0.17 \\
\hline \multicolumn{8}{|c|}{$\begin{array}{l}\text { Glucose from }\left[2-{ }^{14} \mathrm{C}\right] \text { propionate (nmol glucose/ } \\
\text { min per mg dry wt cells) }\end{array}$} \\
\hline & Control & $1.58^{\mathrm{a}}$ & 0.12 & $1 \cdot 16^{\mathrm{b}}$ & 0.11 & $1 \cdot 35^{b}$ & 0.11 \\
\hline & Glucagon & $1.92^{\mathrm{a} *}$ & 0.08 & $1.18^{\mathrm{b}}$ & 0.06 & $1.18^{b}$ & 005 \\
\hline
\end{tabular}

a,b,c Mean values within a row not sharing a common superscript letter were significantly different, $P<0.001$ (a two-tail Student's $t$ test).

* Mean value was significantly different from the corresponding control: $P<0.05$ (a two-tail Student's $t$ test).

$\dagger$ Transport of propionate was determined by incubation of hepatocytes for $30 \mathrm{~s}$ in the presence of $0.5 \mathrm{~mm}$ $\left[2-{ }^{14} \mathrm{C}\right]$ propionate. The rate of gluconeogenesis was determined after incubation of hepatocytes for $10 \mathrm{~min}$ in the presence of $0.5 \mathrm{mM}\left[2-{ }^{14} \mathrm{C}\right]$ propionate. For details, see pp. $784-787$.

\section{Intracellular concentration of propionate}

The intracellular concentrations of propionate were examined after 10 min incubation of hepatocytes at an initial concentration of propionate of $0 \cdot 1-1 \mathrm{mM}$. The concentrations of propionate in the medium and in the intracellular fluid at the end of the 10 min incubation period are shown in Table 3. The intracellular: extracellular propionate ratio was about 10 when the concentration in the medium was $0.04 \mathrm{mM}$ (initial concentration, $0.1 \mathrm{mM}$ ) and the ratio decreased to about 1 as the concentration of propionate in the medium reached $0.4 \mathrm{mM}$ (initial concentration, $1 \mathrm{mM}$ ). No propionate could be detected in the intracellular fluid of hepatocytes incubated in the absence of medium propionate (results not shown). The mean intracellular concentrations of propionate in the hepatocytes isolated from control and glucagon-treated sheep when incubated at an initial concentration of $0.5 \mathrm{mM}$ propionate were 0.35 (SE 0.09) and 0.20 (SE 0.10) mM respectively. When hepatocytes (control group) were incubated in the presence of $1.35 \mathrm{mM}$ butyrate or $10 \mu \mathrm{M}$-rotenone (initial

Table 3. Intracellular and extracellular concentrations of propionate in isolated sheep hepatocytes incubated for $10 \mathrm{~min}$ in the presence of $0.1-1 \mathrm{mM}$ propionate in the incubation medium $\dagger$

(Values are means with their standard errors for three animals)

\begin{tabular}{|c|c|c|c|c|c|}
\hline \multirow{2}{*}{$\begin{array}{l}\text { Initial propionate concentration } \\
\text { in the medium }(\mathrm{mM})\end{array}$} & \multicolumn{2}{|c|}{ Extracellular } & \multicolumn{2}{|c|}{ Intracellular } & \multirow[b]{2}{*}{ Intracellular : extracellular ratio } \\
\hline & Mean & $\mathrm{SE}$ & Mean & $\mathrm{SE}$ & \\
\hline 0.10 & 0.04 & 0.01 & 0.39 & 0.17 & 9.75 \\
\hline 0.25 & 0.07 & 0.01 & 0.36 & $0 \cdot 12$ & $5 \cdot 14$ \\
\hline 0.50 & $0 \cdot 10$ & 0.01 & 0.31 & 0.01 & $3 \cdot 10$ \\
\hline 0.75 & 0.26 & 0.09 & 0.47 & 0.11 & 1.81 \\
\hline 1.00 & 0.37 & 0.04 & 0.40 & 0.04 & 1.08 \\
\hline
\end{tabular}

† For details of procedures, see pp. 786-787. 
concentration $0.5 \mathrm{mM}$-propionate in the medium), the intracellular concentrations of propionate were 0.23 (SE 0.10$)$ and 0.08 (SE $0 \cdot 10) \mathrm{mM}$ respectively.

\section{DISCUSSION}

Using the caudal lobe it was shown that the non-recirculating perfusion of the caudal was a simple and inexpensive model suitable for physiological studies on propionate metabolism in ruminants. Previous studies on propionate metabolism in vitro have been performed by incubation of hepatocytes or by recirculating perfusion of the isolated liver. Due to rapid metabolism of propionate by the ruminant liver and the associated problem of substrate depletion during incubation and/or perfusion, most in vitro studies of the metabolism of propionate have used excessive concentrations ranging from 2 to $10 \mathrm{mM}$. However, these supraphysiological concentrations of propionate in the medium are likely to result in depletion of the mitochondrial ATP pool (Hampson et al. 1984) and accumulation of propionyl-CoA (Brass et al. 1986) both of which affect cell metabolism. The use of a nonrecirculating perfusion system of liver permits the use of a physiological concentration of propionate in the medium. The use of the caudal lobe, which is only about $5 \%$ of the weight of whole liver, reduces the cost of perfusion by minimizing the volume of perfusion medium needed. By using such a system we have shown previously that perfusion of the caudal lobe of the sheep liver with a medium containing glucagon for 30 min resulted in stimulation of glycogenolysis but not gluconeogenesis from propionate (Jois et al. 1993). In the present experiment, intravenous infusion in vivo of glucagon for $3 \mathrm{~h}$ resulted in stimulation of gluconeogenesis from propionate in the subsequently isolated and perfused caudal lobe of the liver. The difference in the response to glucagon in these two studies could be due to the duration for which the liver was exposed to elevated levels of glucagon. It is also possible that the liver tissue is more sensitive to hormonal stimulation in vivo. This stimulation was accompanied by increases in both net uptake and extraction of propionate by the liver. The effect of glucagon infusion in vivo was evident by the marked increase in plasma glucose concentration. The biphasic nature of the plasma glucose curve of glucagon-treated animals suggested depletion of glycogen by glucagon. Glucose was included $(4 \mathrm{mM})$ in the perfusion and incubation media to minimize the effects of differences in intracellular glucose concentration in perfusion and incubation studies.

The reasons for the rapid hepatic utilization of propionate are not clear. Sheep hepatocytes utilize propionate more rapidly than rat hepatocytes (Demigné et al. 1986) and a distinct propionyl CoA synthetase $(E C$ 6.2.1.17) is present in ruminant liver (Ricks \& Cook, 1981). As propionate is charged at physiological $\mathrm{pH}$ and would therefore diffuse slowly into hepatocytes, an effective hepatic transport system for the uptake of propionate is essential to support the rapid metabolism of propionate in the hepatocytes. Fafournoux $e t$ al. (1985) reported that the transport of propionate into rat hepatocytes was mediated by a high-affinity, high-capacity transport system which was not concentrative and exhibited an apparent $K_{\mathrm{m}}$ for propionate of $0.15 \mathrm{mM}$. Results from the present study suggest that the uptake of propionate in sheep hepatocytes is also mediated by a transport system. The $K_{\mathrm{m}}$ for propionate of $0.24 \mathrm{mM}$ observed in the present study was similar to that reported by Fafournoux et al. (1985) but the $\mathrm{V}_{\max }$ was about three times higher. It is apparent from our studies on the distribution of propionate between intra- and extracellular spaces that the transport of propionate by sheep hepatocytes is highly concentrative. Also, inclusion of rotenone, an inhibitor of respiration, markedly decreased the intracellular concentration of propionate. While these data are consistent with active transport of propionate into sheep hepatocytes, transport studies in enzyme-free systems such as studies using plasma 
membrane vesicles are required before firm conclusions can be drawn. The differences in the characteristics of propionate transport in the sheep could be due to adaptation to a much higher concentration of propionate in the portal vein.

Butyrate and caproate, which are potent inhibitors of gluconeogenesis (Demigné $e t$ al. 1986; Aiello et al. 1989; Chow \& Jesse, 1992), were used with the aim of studying transport of propionate in the absence of extensive metabolism. Results from the present study confirmed the inhibitory effects of butyrate and caproate on gluconeogenesis from propionate. However, as the results show (Table 2), both butyrate and caproate were also potent inhibitors of propionate transport into sheep hepatocytes. The inhibitory effects of butyrate on utilization of propionate by ruminant liver are therefore due to inhibition of transport as well as inhibition of metabolism of propionate subsequent to transport into the hepatocytes. The abolition of the effects of glucagon on gluconeogenesis from propionate by butyrate and caproate suggest that the site of inhibition of propionate metabolism by these inhibitors precedes the site of stimulation by glucagon.

It appears from the results of studies in rats that there are two distinct types of actions of glucagon on hepatic metabolism. First is the regulation of cytoplasmic enzymes such as glycogen phosphorylase (EC 2.4.1.1), pyruvate kinase (EC 2.7.1.40), and phenylalanine hydroxylase $(E C$ 1.14.16.1) by protein phosphorylation (Garrison et al. 1984). These effects are typically labile in that the effects are readily reversible due to the actions of protein phosphatases on removal of the hormone. The demonstration of these effects requires careful preparation of tissues using phosphatase inhibitors. The second type of action of glucagon is relatively stable in that the effects persist for some time after the removal of the hormone and can be demonstrated in tissues from animals treated with glucagon isolated without any precautions to preserve the phosphorylation status of proteins. These effects typically include mitochondrial events such as glutaminase ( $E C$ 3.5.1.2) activity, citrulline synthesis, pyruvate transport and glycine oxidation (see Halestrap, 1989; Jois \& Brosnan, 1993). The results from the present study suggest that the effect of glucagon on gluconeogenesis from propionate belongs to this second type of action. The precise mechanism by which glucagon affects mitochondrial metabolism is not clear. Halestrap (1989) has proposed a scheme for the effects of glucagon on mitochondrial metabolism. According to this scheme, glucogenic hormones such as glucagon, catecholamines and vasopressin cause an increase in the mitochondrial matrix volume brought about by an increase in mitochondrial pyrophosphate levels. The increased matrix volume is sufficient to produce, by as yet unknown mechanism(s), activation of respiration, hydrolysis of glutamine, citrulline synthesis, ATP production etc. Further work is needed to define the relationship between the changes in mitochondrial matrix volume and propionate metabolism.

\section{REFERENCES}

Adams, A. J. A. \& Haynes, R. C. Jr (1969). Control of hepatic mitochondrial $\mathrm{CO}_{2}$ fixation by glucagon, epinephrine, and cortisol. Journal of Biological Chemistry 244, 6444-6450.

Aiello, R. J., Armentano, L. E., Bertics, S. J. \& Murphy, A. T. (1989). Volatile fatty acid uptake and propionate metabolism in ruminant hepatocytes. Journal of Dairy Science 72, 942-949.

Bassett, J. M. (1972). Plasma glucagon concentrations in sheep: their regulation and relation to concentration of insulin and growth hormone. Australian Journal of Biological Chemistry 25, 1277-1287.

Bergman, E. N. (1990). Energy contributions of volatile fatty acids from the gastrointestinal tract in various species. Physiological Reviews 70, 567-590.

Bergman, E. N., Roe, W. E. \& Kon, K. (1966). Quantitative aspects of propionate metabolism and gluconeogenesis in sheep. American Journal of Physiology 211, 793-799.

Bergman, E. N. \& Wolff, J. E. (1971). Metabolism of fatty acids by liver and portal-drained viscera in sheep. American Journal of Physiology 221, 586-592. 
Bergmeyer, H. U. \& Bernt, E. (1974). Determination of glucose with glucose oxidase and peroxidase. In Methods of Enzymatic Analysis, vol. 3, pp. 1205-1215 [H. U. Bergmeyer, editor]. New York: Academic Press.

Brass, E. P., Fennessey, P. V. \& Miller, L. V. (1986). Inhibition of oxidative metabolism by propionic acid and its reversal by carnitine in isolated hepatocytes. Biochemical Journal 236, 131-136.

Brockman, R. P. \& Bergman, E. N. (1975). Effect of glucagon on plasma alanine and glutamine metabolism and hepatic gluconeogenesis in sheep. American Journal of Physiology 228, 1627-1633.

Brockman, R. P. \& Greer, C. (1980). Effects of somatostatin and glucagon on the utilization of $\left[2-{ }^{14} \mathrm{C}\right]$ propionate in glucose production in vivo in sheep. Australian Journal of Biological Sciences 33, $457-464$.

Chow, J. C. \& Jesse, B. W. (1992). Interactions between gluconeogenesis and fatty acid oxidation in isolated sheep hepatocytes. Journal of Dairy Science 75, 2142-2149.

Clark, M. G., Filsell, O. H. \& Jarrett, I. G. (1976). Gluconeogenesis in isolated intact lamb liver cells: effects of glucagon and butyrate. Biochemical Journal 156, 671-680.

Demigné, C., Yacoub, C., Morand, C. \& Rémésy, C. (1991). Interactions between propionate and amino acid metabolism in isolated sheep hepatocytes. British Joumal of Nutrition 65, 301-317.

Demigné, C., Yacoub, C., Rémésy, C. \& Fafournoux, P. (1986). Propionate and butyrate metabolism in rat or sheep hepatocytes. Biochimica et Biophysica Acta 875, 535-542.

Donkin, S. S. \& Armentano, L. (1995). Insulin and glucagon regulation of gluconeogenesis in preruminating and ruminating bovine. Journal of Animal Science 73, 546-551.

Fafournoux, P., Rémésy, C. \& Demigné, C. (1985). Propionate transport in rat liver cells. Biochimica et Biophysica Acta 818, 73-80.

Faulkner, A. \& Pollock, H. T. (1986). Propionate metabolism and its regulation by fatty acids in ovine hepatocytes. Comparative Biochemistry and Physiology 84B, 559-563.

Faulkner, A. \& Pollock, H. T. (1990). Effects of glucagon and $\alpha$ - and $\beta$-agonists on glycogenolysis and gluconeogenesis in isolated ovine hepatocytes. Biochimica et Biophysica Acta 1052, 229-234.

Garrison, J. C., Johnsen, D. E. \& Campanile, C. P. (1984). Evidence for the role of phosphorylase kinase, protein kinase $\mathrm{C}$ and other $\mathrm{Ca}^{2+}$-sensitive protein kinases in response of hepatocytes to angiotensin II and vasopressin. Journal of Biological Chemistry 259, 3283-3292.

Gill, W., Mitchell, G. E., Boling, J. A., Tucker, R. E., Schelling, G. T. \& De Gregorio, R. M. (1985). Glucagon influence on gluconeogenesis and oxidation of propionic acid and threonine by perfused ovine liver. Journal of Dairy Science 68, 2886-2894.

Halestrap, A. P. (1989). The regulation of the matrix volume of mammalian mitochondria in vivo and in vitro and its role in the control of mitochondrial metabolism. Biochimica et Biophysica Acta 973, 355-382.

Hampson, R. K., Baron, L. L. \& Olson, M. S. (1984). Stimulation of the glycine cleavage system by short-chain fatty acids in isolated rat liver mitochondria. Biochemistry 23, 4604-4610.

Jensen, C. B., Sistare, F. D., Hamman, H.C. \& Haynes, R. C. Jr (1983). Stimulation of mitochondrial functions by glucagon treatment. Evidence that effects are artifacts of mitochondrial isolation. Biochemical Journal $\mathbf{2 1 0}$, 819-827.

Jois, M. \& Brosnan, J. T. (1993). Hormonal regulation of hepatic glycine metabolism. Australian Journal of Agricultural Research 44, 473-478.

Jois, M., Bunnage, A. P. \& Egan, A. R. (1993). Non-recirculating perfusion of caudal lobe sheep liver to study hepatic metabolism of propionate. Proceedings of XV International Congress of Nutrition, Adelaide, p. 114 Abstr. Adelaide: Smith-Gordon.

Jois, M., Hall, B., Fewer, K. \& Brosnan, J. T. (1989). Regulation of hepatic glycine catabolism by glucagon. Journal of Biological Chemistry 264, 3347-3351.

Judson, G. J., Anderson, E. E., Luick, J. R. \& Leng, R. A. (1968). The contribution of propionate to glucose synthesis in sheep given different diets of different grain contents. British Journal of Nutrition 22, 69-74.

Krebs, H. A., Cornell, N. W., Lund, P. \& Hems, R. (1974). Isolated liver cells as an experimental material. In Regulation of Hepatic Metabolism, pp. 726-750 [F. Lundquist and N. Tygstrup, editors]. New York: Academic Press.

Looney, M. C., Baldwin, R. L. \& Calvert, C. C. (1987). Gluconeogenesis in isolated lamb hepatocytes. Journal of Animal Science 64, 283-294.

Pethick, D. W., Lindsay, D. B., Barker, P. J. \& Northop, A. J. (1981). Acetate supply and utilization by the tissues of sheep in vivo. British Journal of Nutrition 46, 97-110.

Ricks, C. A. \& Cook, R. M. (1981). Regulation of volatile fatty acid uptake by mitochondrial acylCoA synthases of bovine liver. Journal of Dairy Science 64, 2324-2335.

Savan, P. M., Jeacock, M. E. \& Shepherd, D. A. L. (1986). Gluconeogenesis in foetal, suckling and weaned lambs: the effects of glucagon. Journal of Agricultural Science, Cambridge 106, 259-264.

Siess, H. (1978). The use of perfusion of liver and other organs for the study of microsomal electron-transport and cytochrome P-450 systems. Methods in Enzymology 52, 48-59. 